\title{
Effects of Frequent Change of Schools on School Going Children:
}

\section{A Narrative Interpretation}

\author{
Prarthana Saikia ${ }^{1 *}$
}

\section{ABSTRACT}

Changing of environment can have lots of impact on the person's personality. Children of parents, who are in transferrable jobs, have to go through frequent change of schools and cities. This can have a lot of impact in their cognitive and emotional process and can on a whole have impact on their personality. The present study is about how children whose parents are in transferrable jobs cope with their frequent change of their school environment. They go through frequent change of school, leave their old friends and make new friends and adjust to new environment every time their parents gets a new posting. The study was done on 10 adolescents, who had changed their schools at least twice in their life time. They were interviewed about their experience of changing schools. Their emotional and social aspects were taken into accounts. A narrative analysis was done. Through the method of coding, categories and patterns, common themes were developed for analysis.

Keywords: Transferrable Jobs, Change of School, Narrative Analysis

Family and school is said to be two most important places where child transform from mere an individual to an identity that can contribute for society and human kind. Although family is the place where a child encounters first, school also contribute tremendously to the development of the child. Durganand Sinha (1977) in his research on ecological model for understanding the development of children in Indian context included both home and school in upper and most visible layer.

Although most of us belongs to only one family to which we were either born or adopted into, we can change our school for various circumstances. As a child born or adopted into a family, he or she completely depends on it for its protection and for provision of basic needs. Family nurture and tech the child in early years of life till it can enter school. In social sciences, family is define as a socially recognized group (usually joined by blood, marriage, or adoption) that forms

\footnotetext{
${ }^{1}$ Counsellor cum PGT Psychology, Army Public School, Jorhat, Assam, India

*Responding Author

Received: December 29, 2016; Revision Received: January 22, 2017; Accepted: February 2, 2017

(C) 2017 Saikia P; licensee IJIP. This is an Open Access Research distributed under the terms of the Creative Commons Attribution License (www.creativecommons.org/licenses/by/2.0), which permits unrestricted use, distribution, and reproduction in any Medium, provided the original work is properly cited.
} 


\section{Effects of Frequent Change of Schools on School Going Children: A Narrative Interpretation}

an emotional connection and serves as an economic unit of society. Family fulfils emotional and basic needs of a child by providing him/her love, food and care. Parents have custody over their children. As the child reaches school going years his/her parents usually decide about which school their children will enter. They take utter most care in choosing school for their children. School is another area of life where a child can explore himself and herself. Besides cognitive and intellectual development of the child in school, the child also develops socially. School provides an environment where a child enters into a social world. The child learns to make friends, know how to approach other people and how to keep relationships. Schools also take care of child's creativity and other developments.

\section{Change of school}

Although stability of environment is recommended for children, many families today have to move to different places due to various reasons. They move due to change of jobs, business, transfer in jobs, divorce, and separation of parents etc. These moves can bring in stress for parents as well as for children. In China, Lijadi. A. A. and Schalkwyk. G. J. (2014) has done a research on third culture kids (TCK) found that these children struggles in building intimacy and companionships and deep friendships, and also find it difficult to maintaining relationships with others and also fear of commitment in relationship. They found that because of third culture kind's mobility and multicultural lifestyle created difficulties for them to constantly striving for establish and maintain social interaction in their ever-changing world. They have to acquire different skills and adapte and change in order to accepted by their environment.

Movement accompanied by packing, shifting homes and unpacking. Besides these physical changes people also have to go through certain psychological changes. They have to adjust to new environment, make new friends, learning of new culture etc. These changes are along with the change of school for children. Children have to adapt to new course, makeup for courses already done and social pressure of making friends etc. They sometime also have to go through bullying or ragging. Meng. X and Yamauchi. C (2015) found adverse impact of exposure to parental migration on Children's health and educational outcomes.

Movement could also accompanied by change in physical environment and this could affect child's health and well-being. Vutha H, Pide. L and Dalis. P (2014) in their research found that children of migrating parents have impact on wellbeing. Their result shows that children of migrating parents have poor school attendance and school dropout is also high for these children. Although migration is found to have no significant impact on vaccination of children, it does affect the health of children evident by increasing number of injuries and illnesses as well as malnutrition. (Vutha H, et. al., 2014). But there are some other researches shows no such effects. Murphey. D, Bandy. T, Moore. K. A. (2012) done a quantitative research on young children's well-being who frequently moves their residence. In their research they have not found any obvious harm to well-being of children who frequently move their residence. Although they have 


\section{Effects of Frequent Change of Schools on School Going Children: A Narrative Interpretation}

said that they have selected only limited set of wellbeing measures and so might have missed some important aspects of child's experience.

Learning a new language in a new place along with other adjustment itself could create more stress. This is even so true in country like India where each state has its own native language and within a state it has several variations. Language played crucial role for TCKs, as a valuable skill to blend in, to communicate and to make friends. (Lijadi. A. A. and Schalkwyk. G. J., 2014). They have also found that despite having lived in many different contexts (countries or cultures) and speaking different languages, the TCKs in their collage preferred to use magazines in the language that they were familiar with and used in their everyday lives within the family.

\section{Cultural shock}

Going to another culture may also accompanied by cultural shock. People come across new values, new practices, and way of living. When people's own culture doesn't match with another culture they usually experience cultural shock. This may also be true for children, although children are more flexible than adults. There are five stages of cultural shock that people usually go through. First is honeymoon phase, where people may be excited to enter the new culture. They are excited, happy, expect good things. Second phase is called rejection phase. In this phase people come across new problems in new culture and this lead to tension and confusion. In third phase, i.e. regression phase, people move backward, spend much time speaking own language, eat food from home etc. Forth phase is called recovery phase, where people become more comfortable with the language and also feel comfortable with new customs of new culture. In the last stage, reverse culture shock where people now get culture shock when they return to their original places.

As it can be seen from the above literature family and school both play a crucial role in children's life. Children of parents who are in transferable job have to shift school to move with their parents. The present study aims to explore effect of this frequent change of school on child's emotions and how they cope with it.

\section{METHODOLOGY}

\section{Research questions}

1. What kind of memory they have about their previous schools?

2. How they view the process of changing school?

3. Do children go through the same stages of cultural shock that adult go through?

\section{Design}

This research was conducted using a thematic model design. This model focuses on the content of a narrative: 'what' is said more than 'how' it is said, the 'told' rather than the aspects of 'telling' (Riessman, 2008: 54). The content of the told story is at the centre of thematic analysis. 


\section{Effects of Frequent Change of Schools on School Going Children: A Narrative Interpretation}

There is minimal attention to structures selected by the narrator to tell her/his story, function or contextual details of the stories (CigdemEsin, 2011). The analysis starts with open coding and then common themes are group together to connect it to theoretical framework or to emerge new themes.

\section{Participants and sample}

Participants are in the age group of 12 to 16 years of age. Out of the 10 participants interviewed six were female and four were males. Seven of them have changed 5 to 6 schools at the time of interview. One of the have changed 4 schools and other two have changed 3 schools.

Participants are recruited through purposive sampling. They were asked by research if they want to participate and none of them have refused to participate. Most of their parents work in defence sector. They have lived with both of their parents throughout their life.

\section{Data collection}

A small semi-structured interview was conducted by the researcher with each. Individual interviews were conducted in English language using the following interview guiding questions.

Can you tell me about yourself, your life, your family, and your friends?

How many schools you have changed till now?

Can you tell me about your first day in this school?

Can you tell me about your last day in your previous school?

How you have felt when you first heard from your parents that you have to leave your school?

How you feel now in your new school?

Tell me about any memorial experience you had with your friends in your previous school.

Is there anything else that you want to talk about? I'd love to listen to you.

Interviews were held in a place where privacy could be secured, such as counsellor's room. Content of the inter-view was recorded by noting down participants responds by researcher. Care was taken to record verbatim responses as far as possible.

\section{Data analysis}

A hermeneutics approach was used to analyse the data. The records were read several times to get a general picture of participants' experiences. Preliminary categories were found out initially through coding and some of these codes were clustered to come up with broad themes.

\section{RESULT}

Analysis of the data in the interviews revealed a variety of themes, the predominant five of which will be presented in this paper. They are-

- Sadness

- Emotion provoking Memory 
- Special friend

- Habituation

- Excitement

\section{Sadness}

Participants mentioned that they have experienced sadness while leaving their previous school. Some of them also mentioned they still feel sad that they are away from their friends. For example- one of the participants mentioned.

"I can never forget that day. My friends were very aggressive. They told me not to go. All my friends were very good. I was not feeling good. I meet them at 8pm in night. I left them and promised them that I will come back again.”

\section{Emotion provoking Memory}

There are two kinds of memories that participants expressed. They were related to some kind of past achievements and some traumatic experience that ultimately turned in their favour or learned some important lesson.

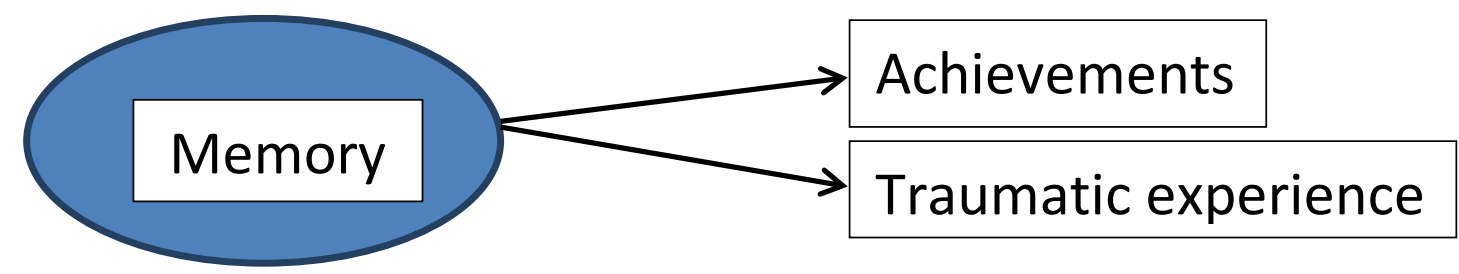

Some of the accounts are as follows

"Deep, a friend of mine, he saved me. Some boys were throwing stones. It was about to hit me. My friend Deep just stood in front of me. And he got hurt instead"

"The place was very memorable for me as I was monitor of the class and also head girl of the school."

\section{Special friend}

The participants mentioned about certain special friend whom they miss a lot. They are still in contact with them and are very sad that they have to leave them and move to new place. One participant mentioned the following account.

"I made a friend in my last school. He was very good. My first day with him was very good. Every day was very memorable with him. We do WhatsApp each other frequently. On my last day he gave me a party and I also gave him a party." 


\section{Effects of Frequent Change of Schools on School Going Children: A Narrative Interpretation}

\section{Habituation}

Participants selected in the study have changed their school several numbers of time. So they are habituated in changing schools and environment. Most of them had no problem in adjusting in their new classroom. They started making friends, shared tiffin and taken note from the first day itself. Following account illustrate theme habituation.

"I came with my parents. We went to principal ma'am. She had taken me to my class. From there I went to assembly. During assembly I met Archita. She explained me about various periods and different things about the class. Then during tiffin break we had tiffin under a tree. I bought bread and omelette and Archita bought pasta. During assembly Epshita was not there. During break I met Epshita and we became friends."

\section{Excitement}

Participants were excited initially when they get to know that they have to change their school. In the interviews almost all of them have used the words curious and excited to describe their first reaction to change of school. Following account illustrate this.

"When my parents told me we are going to north-eastern part of India I was very excited." Another participant told "when my parents told me we are going. I was very excited. I would ask my parents again and again where we are going."

\section{DISCUSSION}

At the onset of the study, the researcher posed three broad research questions:

1. What kind of memory they have about their previous schools?

2. How they view the process of changing school?

3. Do children go through the same stages of cultural shock that adult go through?

The first research question sought to uncover kinds of memory that these children remember from their previous past. From the themes2 it can be seen that children have memories of either some traumatic experience that turned into their favour or they have memories of personal achievements. Children remember some kind of personal achievements like some award, or achievement in friendship or some special positions they have retained in their previous past. They also remember some traumatic experience from which they have learnt something or they were escaped from some serious harm to be caused. These memories have some emotional content that are significant to the participants.

Theme3 reveals that they have some special friends whom they miss a lot. They are in contact with those special friends although they are way apart now. Most of them make use of technology to keep in touch with each other. They use phone to call their friends and use WhatsApp to be in contact with each other. Some of the participants also mentioned the name of the WhatsApp group that they formed to be in contact with each other and what they discuss in those groups. 


\section{Effects of Frequent Change of Schools on School Going Children: A Narrative Interpretation}

The second question sought to uncover how children view their process of moving into different schools. Theme 1 and theme 4 shows that all participants revealed that they were initially very sad with the process but with time they became habituated. All participants mentioned about their crying before leaving their previous station and at the same time excited to go to new station and easily adjusted in it. One participant mentioned that he was previously sad as he had to leave his best friend but was excited too as he love to visit new places. Another participant mentioned that he wanted to contribute to the school in academic and in sports for how much ever time he is part of his present school. Yet another participant told that different schools giving her different opportunities to explore her different talents. So, it can be said that children view their process of moving into new schools frequently as positively.

The third question explore do children go through the same stages of cultural shock that adult go through. With reference to the above mentioned themes, the answer to this question is yes. It can be said that school going participants were excited initially to go to new places i.e. theme 5 . This is correspondent to honeymoon phase. They were sad with the memory of their special friends and special memory i.e. theme 2, theme 3 and theme 5. This correspondent to regression and rejection phase. Ultimately they are well adjusted and habituated i.e. theme 4. This is correspondent to recovery phase.

\section{CONCLUSION}

From the above discussion it can be said that children remember emotional provoking memories, they view the process of changing school as positive and they go through same phase of cultural shock as adults do.

\section{Limitations of the study}

1. Sample size is very less. There were only 10 participants.

2. Selected participants were belongs to affluent families with all the needed facilities.

3. All of them changed their school frequently, so they are used to this process. The results might have turned differently if the selected participants have changed school only one or twice.

\section{Acknowledgments}

The author appreciates all those who participated in the study and helped to facilitate the research process.

Conflict of Interests: The author declared no conflict of interests.

\section{REFERENCES}

Cigdem E., (2011), “Narrative Analysis Approaches.” In Qualitative Research Methods in Psychology, edited by Nollaig Frost, 92-117. McGraw-Hill Open University Press, 


\section{Effects of Frequent Change of Schools on School Going Children: A Narrative Interpretation}

2011http://www.deborahswallow.com/2010/05/15/the-classic-5-stage-culture-shockmodel/ [4 January, 2017, 9:00 pm]

Lijadi,A. A., \& Schalkwyk, G. J.,(2014 ) "Narratives of Third Culture Kids: Commitment and Reticence in Social Relationships, The Qualitative Report 2014,Volume 19, Article 49, pages: 1 to 18

Mazzucatoa, V., Cebotarib, V., Veale, A., White, A., Grassi, M., \&Vivet, J.,(2014), "International Parental Migration and the Psychological Well-being of Children in Ghana, Nigeria, and Angola," Elsevier Social Science \& Medicine, Volume 132, May 2015, Pages 215-224

Meng,X.,\&Yamauchi, C., (2015),“Children of Migrants: The Impact of Parental Migration on Their Children's Education and Health Outcomes,” IZA DP No. 9165,

Murphey, D., Bandy, T.,\& Moore, K. A., (2012),“Frequent Residential Mobility and Young Children's Well-Being," Child Trends,.

Osofsky, J, D., \& Lieutenant Col. Chartrand. Molinda M.,(2013),Military Children from Birth to Five Years, VOL. 23 / NO. 2 / FALL 2013, page: 61 to 77

Pelling, A, C.,(2000) "Culture Shock of International Students in Canada,"

Perreira, K, M., \& Ornelas, I, J.,(2011), "The Physical and Psychological Well-Being of Immigrant Children,” VOL. 21 / NO. 1 / SPRING 2011, page: 195 to 218

Smita,(2008) "Distress Seasonal Migration and its Impact on Children's Education," Consortium for Educational Access, Transitions and Equity, NUEPA

Vutha, H., Pide, L., \&Dalis, P.,(2014), “The Impacts of Adult Migration on Children's Wellbeing: The Case of Cambodia," Cambodia Development Resource Institute, Phnom Penh

Xia Junzi,(2009), “Analysis of Impact of Culture Shock on Individual Psychology,” CCSE International Journal of Psychological Studies, vol1, no.2, page:97 to101

How to cite this article: Saikia P (2017), Effects of Frequent Change of Schools on School Going Children: A Narrative Interpretation, International Journal of Indian Psychology, Volume 4, Issue 2, No. 87, ISSN:2348-5396 (e), ISSN:2349-3429 (p), DIP:18.01.046/20170402, ISBN:978-1-365-71287-6 